\title{
EM BUSCA DE MAIOR AUTONOMIA AOS DEFICIENTES VISUAIS ATRAVÉS DE UM IDENTIFICADOR DE CORES COM AUDIODESCRIÇÃO
}

\section{IN SEARCH OF GREATER AUTONOMY FOR THE VISUALLY IMPAIRED THROUGH A COLOR IDENTIFIER WITH AUDIODESCRIPTION}

\author{
Adhemar Maria do Valle Filho', Dr. \\ Claudia Regina Batista ${ }^{2}$, Dra. \\ (1) Universidade do Valle do Itajaí \\ e-mail: adhe.valle@gmail.com \\ (2) Universidade Federal de Santa Catarina \\ e-mail: claudia.batista@ufsc.br
}

Palavras-chave deficientes visuais, identificador de cores, acessibilidade.

Este artigo apresenta um projeto onde se aplica recursos da tecnologia para contribuir com a inclusão e autonomia das pessoas com deficiência visual. Neste projeto está sendo desenvolvido um aparelho portátil que faz a leitura das cores para os deficientes visuais, ou seja, é feita a identificação da cor em uma determinada superfície e emitida uma audiodescrição para informar a cor.

Key-words visually impaired, color identifier, accessibility.

This article presents a project that applies technology resources to contribute to the inclusion and autonomy of people with visual impairment. In this project is being developed a portable device that makes reading the colors for the visually impaired, that is, the color is identified on a given surface and an audiodescription is issued to inform the color.

\section{Introdução}

Segundo dados do World Report on Disability 2011 e do Vision 2020, a cada cinco segundos, uma pessoa se torna cega no mundo. Além disso, do total de casos de cegueira, $90 \%$ ocorrem nos países emergentes e subdesenvolvidos. Estima-se que, até 2020, o número de pessoas com deficiência visual poderá dobrar no mundo.

Segundo os dados coletados pelo Instituto Brasileiro de Geografia e Estatística - IBGE, no censo demográfico de 2010, a deficiência visual afeta $18,6 \%$ da população brasileira, destas 3,46\% 


\section{$16^{\circ}$ \\ ERGODESIGN USIHC CINAHPA}

com deficiência visual severa. (BRASIL, 2012)

Diante deste cenário e buscando contribuir com a melhoria de qualidade de vida e autonomia dos deficientes visuais, surgiu a iniciativa do projeto apresentado neste artigo, que visa desenvolver um aparelho portátil que faz a identificação das cores e emite uma audiodescrição para informar a cor ao deficiente visual. Neste artigo, na seção 2 faz-se uma abordagem sobre o deficiente visual; na seção 3 volta-se a atenção aos aspectos ligados a inclusão dos deficientes visuais; a seção 4 apresenta algumas contribuições da tecnologia para a autonomia dos deficientes visuais; a seção 5 faz a apresentação do projeto que está desenvolvendo um identificador com audiodescrição das cores para os deficientes visuais; Na última seção, são tecidas as considerações finais.

\section{Deficiente Visual}

Uma deficiência é qualquer perda ou anormalidade da estrutura ou função psicológica, fisiológica ou anatômica. Representa a exteriorização de um estado patológico e, em princípio, reflete distúrbios no nível do órgão. (CIDID, 1993)

\footnotetext{
Pessoas com deficiência são aquelas que têm impedimentos de longo prazo de natureza física, mental, intelectual ou sensorial, os quais, em interação com diversas barreiras, podem obstruir sua participação plena e efetiva na sociedade em igualdades de condições com as demais pessoas. (Convenção sobre os Direitos das Pessoas com Deficiência, artigo $1^{\circ}$ )
}

A deficiência é um tema de direitos humanos e como tal obedece ao princípio de que todo ser humano tem o direito de desfrutar de todas as condições necessárias para o desenvolvimento de seus talentos e aspirações, sem ser submetido a qualquer tipo de discriminação. (BRASIL, 2012)

Os deficientes são seres humanos; pessoas como quaisquer outras, com protagonismos, peculiaridades, contradições e singularidades. Pessoas que lutam por seus direitos, que valorizam o respeito pela dignidade, pela autonomia individual, pela plena e efetiva participação e $16^{\circ}$ Ergodesign - Congresso Internacional de Ergonomia e Usabilidade de Interfaces Humano Tecnológica: Produto, Informações Ambientes Construídos e Transporte

$16^{\circ}$ USIHC - Congresso Internacional de Ergonomia e Usabilidade de Interfaces Humano Computador

CINAHPA | 2017 - Congresso Internacional de Ambientes Hipermídia para Aprendizagem.

inclusão na sociedade e pela igualdade de oportunidades, evidenciando, portanto, que a deficiência é apenas mais uma característica da condição humana. (BRASIL, 2014)

As deficiências podem ser sensoriais, cognitivas, físico-motoras e múltiplas. Dentre as deficiências físicas, está a visual (que há maior ocorrência no Brasil, em relação aos demais tipos).

Segundo Bischoff, Hoffmann e Lunkes (1996), "a deficiência visual é a redução ou perda total da capacidade de ver com o melhor olho mesmo após a melhor correção ótica. Está dividida em cegueira (congênita ou adquirida) e visão subnormal".

Segundo os autores citados:

Cegueira: é a ausência ou perda da visão em ambos os olhos, mesmo com o uso de lentes para correção. É considerada cegueira congênita se a perda da visão ocorrer até três anos; caso ocorra após essa idade, é considerada cegueira adquirida.

[...] Visão Subnormal: acuidade visual entre 6/20 e 6/60 no melhor olho, após correção máxima. Pessoa que têm dificuldade para realizar tarefas visuais inclusive com lentes corretivas. (BISCHOFF; HOFFMANN; LUNKES, 1996)

\section{Inclusão dos deficientes visuais}

Segundo Mantoan (2015): “Inclusão é o privilégio de conviver com as diferenças".

Inclusão é a capacidade de entender e reconhecer o outro e, assim, ter o privilégio de conviver e compartilhar com pessoas diferentes de nós.

Incluir uma pessoa com deficiência significa acolher, estar com ela sem preconceitos, interagir, dar as oportunidades que tem direito.

Algumas ações acontecem na tentativa da inclusão dos deficientes visuais, mas o que se tem feito parece ser muito pouco. Constata-se que as cidades, as escolas, os cinemas, os prédios públicos, enfim, a sociedade brasileira ainda não 


\section{$16^{\circ}$ \\ ERGODESIGN USIHC CINAHPA}

está apta a servir e incluir os deficientes visuais no seu dia-a-dia.

Os direitos de um deficiente visual devem ser usufruídos desde a infância. Na escola:

\begin{abstract}
$\mathrm{O}$ aluno cego tem direito a usar materiais adaptados, como livros didáticos transcritos para o braille ou a reglete para escrever durante as aulas. Antecipe a adaptação dos textos junto dos educadores responsáveis pela sala de recursos, que deve contar com máquinas braille, impressora e equipamentos adaptados. A alfabetização em braille das crianças com cegueira total ou graus severos de deficiência visual é simultânea ao processo de alfabetização das demais crianças na escola, mas com o suporte essencial do Atendimento Educacional Especializado (AEE). (AMPUDIA, 2011)
\end{abstract}

De acordo com o Decreto $\mathrm{N}^{\circ} 7.611$, de 17 de Novembro de 2011, o Estado tem o dever de oferecer apoio técnico e financeiro para que o atendimento especializado esteja presente em toda a rede pública de ensino. Mas, cabem ao gestor da escola e às Secretarias de Educação a administração e o requerimento dos recursos para essa finalidade.

Oferecer ambientes adaptados, com sinalização em braille, escadas com contrastes de cor nos degraus, corredores desobstruídos e piso tátil, é mais uma medida importante para a inclusão de deficientes visuais. O entorno da escola também deve ser acessível, com a instalação de sinais sonoros nos semáforos e nas áreas de saída de veículos próximas da escola. Todas essas medidas de acessibilidade deveriam ser implantadas não somente no entorno das escolas, mas em todos os locais. (AMPUDIA, 2011)

\section{Contribuições da tecnologia para a autonomia dos deficientes visuais}

Autonomia é um termo de origem grega cujo significado está relacionado com independência, liberdade ou autossuficiência. Para os deficientes visuais, conquistar a autonomia é libertador, faz bem para a autoestima, eles se sentem mais $16^{\circ}$ Ergodesign - Congresso Internacional de Ergonomia e Usabilidade de Interfaces Humano Tecnológica: Produto, Informações Ambientes Construídos e Transporte

$16^{\circ}$ USIHC - Congresso Internacional de Ergonomia e Usabilidade de Interfaces Humano Computador

CINAHPA | 2017 - Congresso Internacional de Ambientes Hipermídia para Aprendizagem.

seguros, satisfeitos e felizes.

Para Aciem e Mazzotta (2013):

A autonomia da pessoa com deficiência visual pode ser avaliada em atividades da vida diária, no lazer, na vida emocional, na independência no trajeto de ir e vir, na vida profissional, entre outros. [...] A pessoa com deficiência necessita da segurança com autonomia, de tal maneira, que a encoraje à independência pessoal e à liberdade prevista na Constituição Federal de 1988, com o direito pleno ao exercício da cidadania.

Com o intuito de promover a autonomia dos deficientes visuais, diversas soluções com recursos tecnológicos vêm sendo desenvolvidas e alguns exemplos são apresentados na sequência:

- JAWS (acrônimo para Job Access With Speech) é um programa de computador "leitor de tela" para usuários com deficiência visual, produzido pelo Blind and Low Vision Group da empresa Freedom Scientific, de Saint Petersburg, Flórida, Estados Unidos. (FREEDOM SCIENTIFIC, 2017)

- O sistema operacional DOSVOX permite que pessoas cegas utilizem o computador para desempenhar uma série de tarefas, adquirindo assim um nível alto de independência no estudo e no trabalho. O DOSVOX é um sistema computacional, baseado no uso intensivo de síntese de voz, desenvolvido pelo Instituto Tércio Paciti (antigo Núcleo de Computação Eletrônica - NCE) da Universidade Federal do Rio de Janeiro (UFRJ). (DOSVOX, 2017)

- A bengala eletrônica sinaliza obstáculos para deficiente visual. Ao identificar obstáculos à frente, a bengala emite um sinal sonoro. Quanto mais próximo estiver o objeto, menos intervalos entre os sinais. A bengala eletrônica foi criada por pesquisadores da Faculdade de Engenharia Eletrônica da Fundação Educacional Inaciana FEI. O seu manuseio é simples e os botões de controle possuem legenda em Braille. $\mathrm{O}$ aparelho pode ficar dentro da mochila ou preso na cintura e está apto a identificar qualquer tipo 


\section{$16^{\circ}$ \\ ERGODESIGN USIHC CINAHPA}

de obstáculo, sejam buracos, postes, árvores, entre outros. (ACESSIBILIDADE BRASIL, 2017)

- O SoundSee é um dispositivo portátil (menor que um aparelho celular) que pode ser carregado no bolso. Ele detecta objetos ao redor da pessoa e produz sons, via fone de ouvido. $\mathrm{O}$ deficiente visual consegue sentir a posição de onde vem o som. Mas, o som não está sendo emitido pelo obstáculo, é o equipamento que detecta a posição do obstáculo e produz artificialmente um som que parece estar vindo de um determinado local. O SoundSee utiliza mecanismo de ecolocalização, o mesmo do qual se utilizam alguns animais, como os morcegos, que emitem sons e escutam o eco produzido pelos obstáculos para se guiar. Com o auxílio de um software, que calcula a posição dos obstáculos, o aparelho gera sons tridimensionais que auxiliam o usuário a detectar a presença dos obstáculos. Este equipamento está sendo desenvolvido pelo Instituto de Ciências Matemáticas e de Computação (ICMC) da Universidade de São Paulo (USP), em São Carlos. (PORTAL BRASIL, 2016)

- O medidor de nível para líquidos é um aparelho eletrônico portátil utilizado para a indicação do nível de líquidos em recipientes. Ao ser colocado na borda de um copo, caneca ou outro recipiente, ele emite um sinal sonoro de alta frequência quando o nível do líquido atinge o sensor do aparelho, evitando assim o derramamento do líquido, e a necessidade de se testar com os dedos se o líquido está no nível ideal. Ele pode ser usado com os mais diversos tipos de líquidos quentes ou frios, de densidades diferentes como cafés, chás, refrigerantes, vinhos entre outros. Este aparelho já está sendo comercializado em lojas especializadas em produtos para deficientes visuais. (INCLUSIVA DIGITAL, 2017) $16^{\circ}$ Ergodesign - Congresso Internacional de Ergonomia e Usabilidade de Interfaces Humano Tecnológica: Produto, Informações Ambientes Construídos e Transporte

$16^{\circ}$ USIHC - Congresso Internacional de Ergonomia e Usabilidade de Interfaces Humano Computador

CINAHPA | 2017 - Congresso Internacional de Ambientes Hipermídia para Aprendizagem.

\section{A identificação das cores e audiodescrição para os deficientes visuais}

\subsection{O deficiente visual e a interpretação das cores}

Segundo Pedrosa:

\begin{abstract}
A cor não tem existência material: é apenas sensação produzida por certas organizações nervosas sob a ação da luz - mais precisamente, é a sensação provocada pela ação da luz sobre o órgão da visão. (PEDROSA, 1982, 17)
\end{abstract}

No fenômeno da sensação da cor estão envolvidos os elementos físico (a luz) e fisiológico (o olho: "aparelho receptor, funcionando como decifrador do fluxo luminoso, decompondo-o ou alterando-o através da função seletora da retina"). (PEDROSA, 1982, 17)

A cor é perceptível somente aos olhos, não sendo identificável através de outras percepções sensoriais (tátil, olfativa, auditiva, gustativa).

As cores fazem parte do cotidiano e são usadas para identificar/caracterizar os objetos, os alimentos, os vestuários, os elementos urbanos e paisagísticos, também usadas nos sistemas de sinalização, entre tantos outros códigos visuais.

A cor está relacionada diretamente ao convívio social, por isso é importante que as pessoas com deficiência visual consigam interpretar o significado das cores como as expressões: o céu está azul, o jogador recebeu cartão vermelho, o semáforo está verde, ele está roxo de raiva. Molina (2013) - deficiente visual e pedagoga recomenda:

[...] nunca deixe de explicar e nomear cores para uma pessoa com deficiência visual, elas gostam de participar do mundo "real" das imagens. Descreva as cores, associando-as com algo que esteja ao alcance ou que seja familiar da pessoa cega. Fale sobre imagens, tons, combinação das cores e roupas. Afinal isso também é inclusão! (Molina, 2013)

Dentre os deficientes visuais, alguns possuem 


\section{$16^{\circ}$ \\ ERGODESIGN USIHC CINAHPA}

cegueira adquirida, portanto chegaram a conhecer o mundo e as cores. Dessa forma, é possível ajudar a pessoa a lembrar de determinadas tonalidades usando bastante a descrição. Outros deficientes visuais ainda conseguem enxergar um pouco, mesmo que sejam apenas vultos e são capazes de distinguir entre claro e escuro; e esta capacidade pode ajudá-lo compreender a cor preta (escuro) e o branco (claro, onde há a presença de luz). Já no caso dos cegos congênitos, conforme explica Molina (2013):

[...] as cores vão ganhar significados reais através de associações táteis, olfativas e até gustativas, em alguns casos. O que diferencia, então é o fato das abstrações deixarem de ser visuais e passarem a usar o próprio repertório já construído pela pessoa cega, por meio das texturas, dos aromas e dos gostos que já conhecem. [...] A associação precisa acontecer a partir de objetos, aromas e gostos que the são familiares e que lhes provoquem alguma sensação ou lembrança. Muitos sabem que os cheiros são capazes de nos transportar para situações e momentos diversos vivenciados por nós e, por isso, essa talvez seja a melhor de todas as experiências comparativas. As associações também precisam ser agradáveis ao tato, ao olfato e ao paladar para que não haja a rejeição imediata e a cor passe a ser "feia" na concepção de quem a vê pelos sentidos remanescentes.

\subsection{0 projeto do aparelho portátil para identificar as cores e emitir audiodescrição}

Numa parceria entre o Laboratório de Redes, Controle e Automação da Universidade do Vale do Itajaí e o HiperLab da Universidade Federal de Santa Catarina, está sendo desenvolvido um aparelho portátil que tem a função de fazer a identificação da cor em uma determinada superfície e emitir uma audiodescrição para informar essa cor ao deficiente visual.

Acredita-se que este aparelho cuja funcionalidade é "ver as cores" para os deficientes visuais pode contribuir para que eles adquiram mais autonomia na vida pessoal, escolar, profissional e social. $16^{\circ}$ Ergodesign - Congresso Internacional de Ergonomia e Usabilidade de Interfaces Humano Tecnológica: Produto, Informações Ambientes Construídos e Transporte

$16^{\circ}$ USIHC - Congresso Internacional de Ergonomia e Usabilidade de Interfaces Humano Computador

CINAHPA | 2017 - Congresso Internacional de Ambientes Hipermídia para Aprendizagem.

\subsubsection{Hardware \& software}

O aparelho portátil para identificar as cores e emitir audiodescrição caracteriza-se como um sistema eletrônico embarcado.

\section{Sistemas embarcados são sistemas computacionais completos e independentes, encarregados de executar apenas uma função determinada - tarefas pré-determinadas, com requisitos específicos. Sistemas embarcados estão relacionados ao uso de hardware (eletrônica) e software (instruções) incorporados em um dispositivo com um objetivo pré-definido. (ALMEIDA; MORAES; SERAPHIM, 2016)}

O projeto previu as seguintes etapas de desenvolvimento:

- Modelagem da arquitetura do sistema;

- Estudo, projeto e montagem do módulo de hardware;

- Estudo, projeto e implementação do módulo do software;

- Integração do hardware \& software;

- Desenvolvimento da carcaça do aparelho portátil com comunicação em braille;

- Implementação e testagem;

- Elaboração das especificações do protótipo;

- Documentação dos resultados obtidos;

A arquitetura é composta de componentes de hardware, componentes de software e canais de interconexão (Edwards, et al., 1997). Os microprocessadores, as memórias e os dispositivos de entrada e saída fazem parte do hardware. $\mathrm{O}$ software é composto do sistema operacional, drivers de dispositivos e biblioteca de funções. Os canais de interconexão abrangem os canais abstratos, barramentos e memórias compartilhadas. Para escolher estes componentes é necessário que os requisitos funcionais estejam bem definidos e para auxiliar esta tarefa utilizam-se de simuladores.

Na figura 1, pode-se observar a arquitetura do aparelho que identifica as cores e emite audiodescrição. 
$16^{\circ}$ USIHC - Congresso Internacional de Ergonomia e Usabilidade de CINAHPA Interfaces Humano Computador

CINAHPA | 2017 - Congresso Internacional de Ambientes Hipermídia para Aprendizagem.

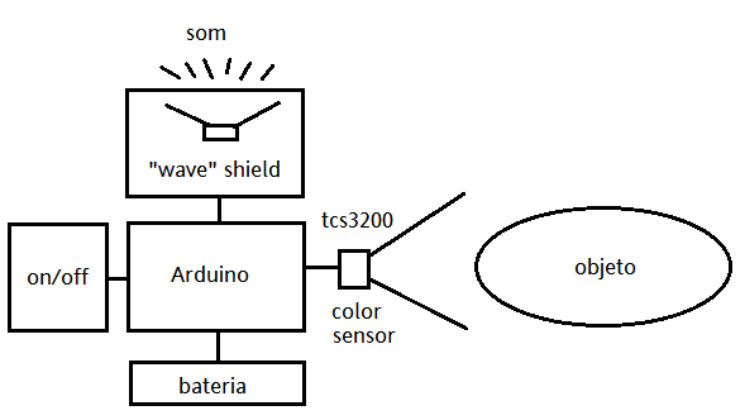

Figura 1 - Arquitetura do sistema Fonte: desenvolvido pelos autores.

A estrutura de hardware divide-se nas seguintes partes: sensor de identificação de cor TCS3200 detecta nível de cores RGB de objetos; a placa principal, shield, o alto-falante e bateria. Possui também um botão de acionamento para ligar ou desligar o sistema.

Dá-se ênfase ao Sensor TCS3200, pois ele é o responsável pela identificação das cores. O módulo é composto por um chip sensor RGB TCS230 e 4 leds que emitem a luz que é captada pelo circuito receptor. O receptor possui 64 fotodiodos, 16 são filtros para a cor vermelha, 16 para a cor verde, 16 para a cor azul e 16 não tem filtro algum. Estes sensores captam a luminosidade, filtrando as cores, e geram na saída um sinal de onda quadrada com as informações sobre a intensidade das cores vermelho $(\mathrm{R}=$ Red $)$, verde $(\mathrm{G}=$ Green) e Azul (B $=$ Blue $)$. Respostas com mistura das tonalidades pode resultar em um sistema Fuzzy ${ }^{1}$.

Conforme mostra o módulo (figura 2), o sensor TCS230 vem montado em conjunto com quatro leds brancos para iluminação e oito pinos para conexão. $\mathrm{O}$ módulo aceita alimentação de 3 à 5 volts e são utilizados 5 pinos para conexão ao Arduino: os pinos de controle S0, S1, S2, S3, e o pino OUT, que é o responsável pelo envio das informações. (TAOS, 2016)

\footnotetext{
${ }^{1}$ A lógica Fuzzy (difusa) é a forma de lógica multivalorada na qual os valores lógicos das variáveis podem ser qualquer número real entre 0 (falso) e 1 (verdadeiro). Foi estendida para lidar com o conceito de verdade parcial, onde o valor verdade pode compreender entre completamente verdadeiro e completamente falso. (AHLAWAT et al., 2014)
}

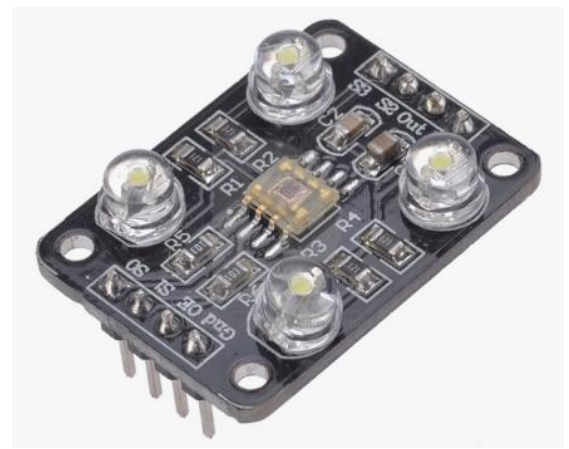

Figura 2 - Módulo com o sensor TCS230 Fonte: Instituto Digital, 2016.

Para a integração do hardware \& software foram utilizados os dispositivos Arduino que utilizam uma linguagem própria Wiring.

Arduino é uma plataforma de prototipagem eletrônica de código aberto baseada em hardware e software fáceis de usar. Numa placa única, projetada com um microcontrolador Atmel AVR com suporte de entrada/saída embutido, uma linguagem de programação padrão, a qual tem origem em Wiring, e é essencialmente $\mathrm{C} / \mathrm{C}++. \mathrm{O}$ objetivo do projeto é criar ferramentas que são acessíveis, com baixo custo, flexíveis e fáceis de usar por artistas e amadores. [...] Pode ser usado para o desenvolvimento de objetos interativos independentes, ou ainda para ser conectado a um computador hospedeiro. Uma típica placa Arduino é composta por um controlador, algumas linhas de E/S digital e analógica, além de uma interface serial ou USB, para interligar-se ao hospedeiro, que é usado para programá-la e interagi-la em tempo real. (ARDUINO, 2017)

Para o funcionamento do áudio foi necessário um shield - Adafruit Wave Board (ver fig. 3). As características desta placa são as seguintes: amostrar arquivos de áudio em $22 \mathrm{kHz}, 12$ bits, possui um Conversor Digital Analógico na placa, filtro e op-amp para a saída de alta qualidade. Os arquivos de áudio são lidos de um cartão SD / MMC O volume pode ser controlado com o potenciômetro botão giratório.
Realização:

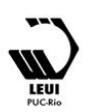


$16^{\circ}$ USIHC - Congresso Internacional de Ergonomia e Usabilidade de CINAHPA Interfaces Humano Computador

CINAHPA | 2017 - Congresso Internacional de Ambientes Hipermídia para Aprendizagem.

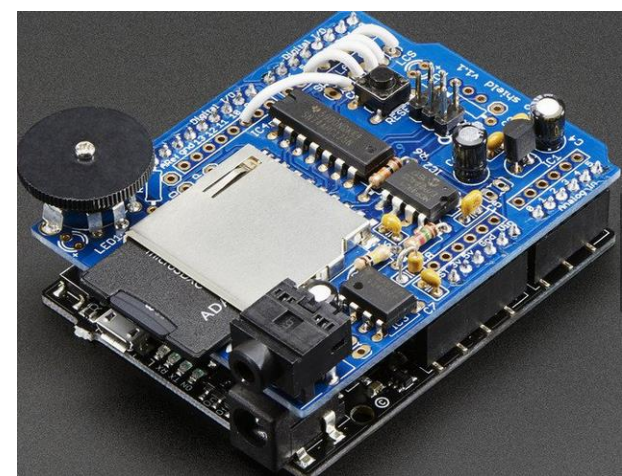

Figura 3 - Placa Adafruit Wave Shield para Arduino Fonte: Adafruit, 2016.

As dimensões do aparelho são $5 \mathrm{~cm} \times 5 \mathrm{~cm} \times 1 \mathrm{~cm}$. Em relação ao processo de fabricação, a carcaça será moldada por injeção, produzida em $\mathrm{ABS}^{2}$ : um termoplástico rígido e leve, com alguma flexibilidade e resistência na absorção de impacto, muito comum na fabricação de produtos moldados para usos diversos. O ABS possui uma excelente relação de preço qualidade, ou seja, é econômico e eficaz. Conforme mostra a figura 4 , na face frontal do aparelho, logo abaixo do botão, há orientação em braille para o deficiente visual: "aperte aqui para saber a cor".
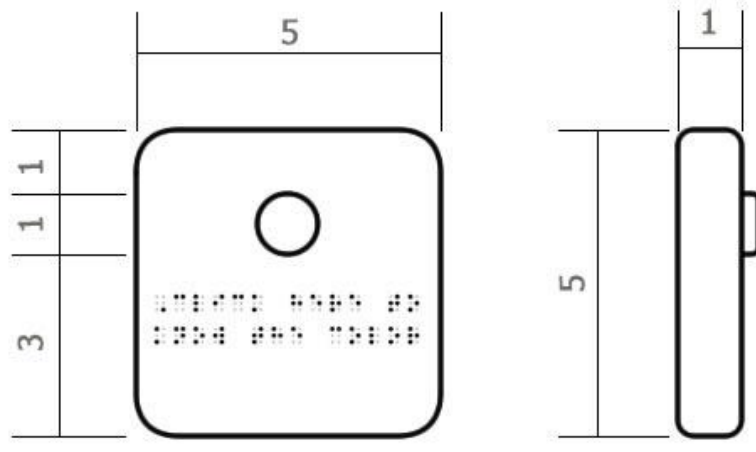

Unid.: $\mathrm{cm}$

Figura 4 - Dimensões do aparelho Fonte: desenvolvido pelos autores.

\footnotetext{
${ }^{2} \mathrm{ABS}$ é a sigla para Acrilonitrila butadieno estireno, é um copolímero composto pela combinação de acrilonitrila, butadieno e estireno. A sua fórmula química é

$\left(\mathrm{C}_{8} \mathrm{H}_{8} \cdot \mathrm{C}_{4} \mathrm{H}_{6} \cdot \mathrm{C}_{3} \mathrm{H}_{3} \mathrm{~N}\right)_{\mathrm{n}}$, e a proporção exata de cada componente na composição do copolímero depende da utilização final do produto para que este se destina.
}

\subsubsection{A interação com o usuário}

O funcionamento é rápido e fácil, basta o deficiente visual aproximar o aparelho do objeto que ele deseja saber a cor e pressionar o botão, tal como pode ser visto na figura 5 . O dispositivo emite uma luz e um receptor captará a cor que estará sendo refletida. Na sequência, uma descrição em áudio é emitida para informar a cor do objeto.
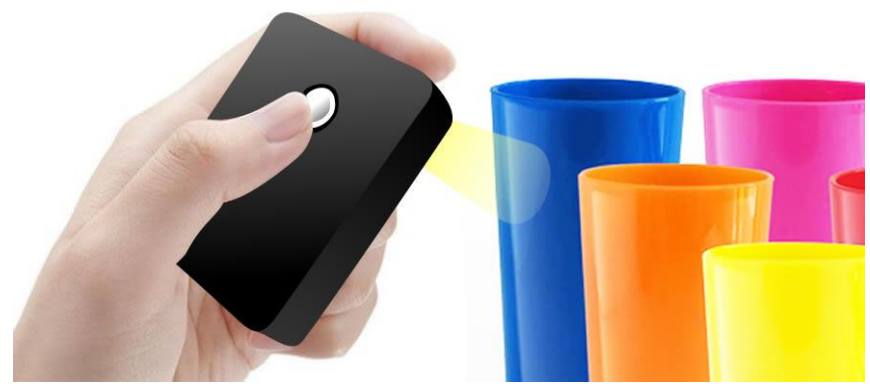

Figura 5 - A interação entre usuário-aparelho Fonte: desenvolvido pelos autores.

\section{Considerações Finais}

Após ter sido projetada a estrutura de hardware, que deve obedecer aos requisitos funcionais especificados, deu-se o início ao desenvolvimento do software que deve contemplar a identificação da cor e a ativação do áudio relativo a cor captada pelo sensor TCS3200.

No estágio atual, está sendo verificado se o funcionamento e integração Software \& Hardware contemplam todos os requisitos. Nesta etapa está sendo regulada a precisão do sensor, estão sendo feitos os ajustes necessários para contemplar o máximo possível de cores. Para a validação, algumas pessoas serão selecionadas para fazer um teste de cores e aprovar o funcionamento do dispositivo.

Em relação ao áudio, em estudos futuros, outras configurações como idioma, voz feminina, masculina também podem ser implementadas.

Finalizando, observa-se a relevância social deste projeto, pois o produto pode contribuir para a melhoria da qualidade de vida, a inclusão social e propiciar maior autonomia aos deficientes visuais.
Realização:
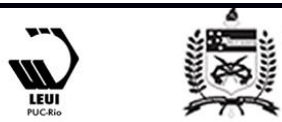
$16^{\circ}$ Ergodesign - Congresso Internacional de Ergonomia e Usabilidade de Interfaces Humano Tecnológica: Produto, Informações Ambientes Construídos e Transporte

$16^{\circ}$ USIHC - Congresso Internacional de Ergonomia e Usabilidade de Interfaces Humano Computador

CINAHPA | 2017 - Congresso Internacional de Ambientes Hipermídia para Aprendizagem.

\section{Bibliografia}

ACESSIBILIDADE BRASIL. Bengala eletrônica sinaliza obstáculos para o deficiente visual. Disponível em http://www.acessibilidadebrasil.org.br/joomla/notic ias/548-bengala-eletronica-sinaliza-obstaculospara-o-deficiente-visual, acesso em 10/01/2017.

ACIEM, T. M; MAZZOTTA, M. J. S. Autonomia pessoal e social de pessoas com deficiência visual após reabilitação. Revista Brasileira de

Oftalmologia, v.72, n. 4, Rio de

Janeiro, July/Aug. 2013. Disponível online em http://www.scielo.br/scielo.php?script=sci_arttext \&pid=S0034-72802013000400011, acesso em 15/01/2017.

ADAFRUIT. Adafruit Wave shield for Arduino, Disponível online em

https://www.adafruit.com/products/94, acesso em 05/06/2016.

AHLAWAT, NISHANT, ASHU GAUTAM, AND NIDHI SHARMA. Use of logic gates to make edge avoider robot. International Journal of Information \& Computation Technology, v.4, Issue 6; p. 630, April 2014.

ALMEIDA, R. M; MORAES, C. H. V; SERAPHIM, T. F. P. Programação de Sistemas Embarcados: Desenvolvendo software para microcontroladores em linguagem C. Rio de Janeiro: Elsevier, 2016.

AMPUDIA, R. O que é deficiência visual? 2011. In: Nova escola. Disponível em https://novaescola.org.br/conteudo/270/deficienciavisual-inclusao, acesso em 10/01/2017.

ARDUINO. What is arduino? Disponível em https://www.arduino.cc/en/Guide/Introduction, acesso em 10/01/2017.

BESSA, O. F. M. A agradabilidade do espaço urbano construído da cidade de Alfenas (MG): uma abordagem ergonômica. Rio de Janeiro: PUCRio, 2001.
BISCHOFF, A. R; HOFFMANN, L. T; LUNKES, L. Deficiência Visual. In: CAMARGO, N. F; GONZALEZ, S. J. Desporto adaptado portadores de deficiência: natação. Porto Alegre: UFRGS, INDESP, 1996.

BRASIL. Cartilha do Censo 2010 - Pessoas com Deficiência. Brasília: Secretaria Nacional de Promoção dos Direitos da Pessoa com Deficiência, 2012.

BRASIL. Manual de Orientação e Apoio para Atendimento às Pessoas com Deficiência. Brasília: Secretaria Nacional de Promoção dos Direitos da Pessoa com Deficiência, 2014.

CULLEN, G. Paisagem Urbana. Lisboa: Edições 70, 1996.

EDWARDS, S. LAVAGNO, L. LEE, E.A. SANGIOVANNI-VINCENTELLI, A. Design of embedded systems: formal models, validation, and synthesis. Proceedings of the IEEE, California Univ., Berkeley, CA, Mar 1997.

DOSVOX. Projeto DOSVOX. Disponível em http://intervox.nce.ufrj.br/dosvox/, acesso em 10/01/2017.

FREEDOM SCIENTIFIC. JAWS Headquarters. Disponível em http://www.freedomscientific.com/JAWSHQ/JAW SHeadquarters01, acesso em 10/01/2017.

Fundação Dorina Nowill para Cegos. O que é deficiência? Disponível em https://www.fundacaodorina.org.br/afundacao/deficiencia-visual/o-que-e-deficiencia/, acesso em 10/01/17.

INCLUSIVA DIGITAL. Medidor de Nível para Líquidos Portátil. Disponível em http://www.inclusivadigital.com.br/item/medidorde-n\%EDvel-para-1\%EDquidos-port\%E1 til.html, acesso em 10/01/17.

INSTITUTO DIGITAL. Módulo sensor de reconhecimento de cor TCS230. Disponível em http://www.institutodigital.com.br/pd-182e61modulo-sensor-de-reconhecimento-de-cor- 


\section{$16^{\circ}$ \\ ERGODESIGN USIHC CINAHPA}

$16^{\circ}$ Ergodesign - Congresso Internacional de Ergonomia e Usabilidade de Interfaces Humano Tecnológica: Produto, Informações Ambientes Construídos e Transporte

$16^{\circ}$ USIHC - Congresso Internacional de Ergonomia e Usabilidade de Interfaces Humano Computador

CINAHPA | 2017 - Congresso Internacional de Ambientes Hipermídia para Aprendizagem.

tcs230.html, acesso em 12/09/16.

MANTOAN, M. T. E. Inclusão escolar: o que é? Por que? Como fazer? São Paulo: Summus Editorial, 2015.

MOLINA, L. Posso ensinar cores a uma pessoa cega? In: Guia Inclusivo, 2013. Disponível em http://www.guiainclusivo.com.br/2013/09/possoensinar-cores-uma-pessoa-cega/, acesso em 07/12/16.

PEDROSA, I. Da cor à cor inexistente. $3^{\text {a }}$ Ed. Rio de Janeiro: Ed. Universidade de Brasília, 1982.

PORTAL BRASIL. Tecnologia com sons ajuda cegos a perceberem objetos. In: Ciência e Tecnologia, 29/02/2016. Disponível em http://www.brasil.gov.br/ciencia-etecnologia/2016/02/tecnologia-com-sons-ajudacegos-a-perceberem-objetos, acesso em 07/12/16.

TAOS. TCS230 programmable color light-tofrequency converter. Disponível em www.pobot.org/IMG/pdf/tcs230_datasheet.pdf, acesso em 14/07/2016.

WERNECK, Claudia. Ninguém mais vai ser bonzinho na sociedade inclusiva. $2^{\mathrm{a}}$. ed., Rio de Janeiro: WVA, 2000. p. 52.

World Health Organization. World report on disability 2011. Geneva: WHO Press, 2011. 